\title{
Corrigendum: Characterization of SARS-CoV-2 Variants N501Y.V1 and N501Y.V2 Spike on Viral Infectivity
}

\author{
Haijun Tang ${ }^{1,2}$, Long Gao ${ }^{1,2}$, Zhao Wu ${ }^{1,2}$, Fang Meng ${ }^{1,2}$, Xin Zhao 1,2, Yun Shao ${ }^{1,2}$, \\ Xiaohua Shi ${ }^{3}$, Shigang Qiao ${ }^{4}$, Jianzhong $A n^{4}$, Xiaohong $\mathrm{Du}^{4 *}$ and F. Xiao-Feng Qin ${ }^{1,2^{\star}}$ \\ 1 Institute of Systems Medicine, Chinese Academy of Medical Sciences \& Peking Union Medical College, Beijing, China, \\ 2 Suzhou Institute of Systems Medicine, Suzhou, China, ${ }^{3}$ Department of Gastroenterology, The Affiliated Suzhou Science \\ and Technology Town Hospital of Nanjing Medical University, Suzhou, China, ${ }^{4}$ Institute of Clinical Medicine Research, \\ Suzhou Science and Technology Town Hospital, The Affiliated Suzhou Hospital of Nanjing Medical University, Suzhou, China
}

\section{OPEN ACCESS}

Approved by:

Frontiers Editorial Office,

Frontiers Media SA, Switzerland

*Correspondence:

Xiaohong Du dx14857@126.com

F. Xiao-Feng Qin

fain1@foxmail.com

Specialty section:

This article was submitted to

Virus and Host,

a section of the journal

Frontiers in Cellular and

Infection Microbiology

Received: 12 November 2021 Accepted: 16 November 2021

Published: 29 November 2021

Citation:

Tang H, Gao L, Wu Z, Meng F, Zhao X,

Shao Y, Shi X, Qiao S, An J, DuX and Qin FX-F (2021) Corrigendum:

Characterization of SARS-COV-2

Variants N501Y.V1 and N501Y.V2

Spike on Viral Infectivity.

Front. Cell. Infect. Microbiol. 11:813645.

doi: 10.3389/fcimb.2021.813645
Keywords: SARS-CoV-2, N501Y.V1, N501Y.V2, infectivity, thermal stability

\section{A Corrigendum on}

Characterization of SARS-CoV-2 Variants N501Y.V1 and N501Y.V2 Spike on Viral Infectivity By Tang H, Gao L, Wu Z, Meng F, Zhao X, Shao Y, Shi X, Qiao S, An J, Du X and Qin FX-F (2021). Front. Cell. Infect. Microbiol. 11:720357. doi: 10.3389/fcimb.2021.720357

\section{INCORRECT AFFILIATION}

In the published article, there was an error in affiliation 1. Instead of " ${ }^{\text {Cl }}$ Center of Systems Medicine, Institute of Basic Medical Sciences, Chinese Academy of Medical Sciences and Peking Union Medical College, Beijing, China" it should be "11 Institute of Systems Medicine, Chinese Academy of Medical Sciences \& Peking Union Medical College, Beijing, China”.

We apologize for these errors and state that these do not change the scientific conclusions of the article in any way. The original article has been updated.

Publisher's Note: All claims expressed in this article are solely those of the authors and do not necessarily represent those of their affiliated organizations, or those of the publisher, the editors and the reviewers. Any product that may be evaluated in this article, or claim that may be made by its manufacturer, is not guaranteed or endorsed by the publisher.

Copyright $\odot 2021$ Tang, Gao, Wu, Meng, Zhao, Shao, Shi, Qiao, An, Du and Qin. This is an open-access article distributed under the terms of the Creative Commons Attribution License (CC BY). The use, distribution or reproduction in other forums is permitted, provided the original author(s) and the copyright owner(s) are credited and that the original publication in this journal is cited, in accordance with accepted academic practice. No use, distribution or reproduction is permitted which does not comply with these terms. 